\title{
La fraseología en el aula de E/LE: ¿un reto difícil de alcanzar? Una aproximación a la fraseodidáctica
}

\author{
Agnieszka SzYNDLER \\ Universidad de Silesia (Katowice, Polonia) \\ Instituto de Lenguas Románicas y de Traducción \\ Departamento de Hispánicas \\ agnieszka.szyndler@us.edu.pl
}

Recibido: 10 de septiembre de 2014

Aceptado: 3 de octubre de 2015

\section{RESUMEN}

En el presente artículo nos proponemos presentar una visión general de la fraseodidáctica, una disciplina relativamente nueva que, hoy en día, gracias a un considerable número de trabajos centrados en diferentes aspectos concernientes a la enseñanza de lenguas, se ha convertido en un campo de estudio independiente. Así pues, no solo explicaremos la definición del concepto fraseodidáctica, sino también su evolución y objetivos. Además, presentaremos los motivos por los cuales la fraseología debe contemplarse como una materia imprescindible e insoslayable en el aula de E/LE, así como indagaremos en diversas propiedades fraseológicas que dificultan tanto la labor del docente como el proceso discente. Finalmente, partiendo de las ideas desarrolladas, ofreceremos consideraciones metodológicas generales con interesantes implicaciones didácticas.

Palabras clave: fraseodidáctica, proceso de enseñanza-aprendizaje de la fraseología, unidades fraseológicas, Español Lengua Extranjera.

The phraseology in teaching Spanish as a foreign language (SFL). Is it a challenge? An approach to Phraseodidactics

\begin{abstract}
The aim of this article is to give a general overview of Phraseodidactics, a relatively new discipline which, nowadays, thanks to a large number of papers focusing on different aspects of language teaching, has become an independent field of study. Thus, not only do we explain the notion of 'Phraseodidactics', but also we analyze its evolution and objectives. In addition, we present the reasons why phraseology should be considered a vital element while teaching Spanish as a foreign language. Moreover, we investigate various phraseological aspects that can hinder the work of the teachers and the learning process of the students. Finally, based on the developed ideas, we offer general methodological considerations with interesting educational implications.

Key words: didactic of phraseology, teaching and learning process of phraseology, phrasems, Spanish as a foreign language.
\end{abstract}


La phraséologie en classe d'ELE : un défi difficile à atteindre ? Une approximation à la phraséodidactique

\section{RÉSUMÉ}

Dans le présent article, nous nous proposons de présenter une vision générale de la phraséodidactique, une discipline relativement nouvelle qui, de nos jours, grâce à un grand nombre de travaux portant sur différents aspects liés à l'enseignement des langues, est devenue un champ d'étude indépendant. Ainsi, nous expliquerons non seulement la définition du concept phraséodidactique, mais aussi son évolution et ses objectifs. En outre, nous présenterons les raisons pour lesquelles la phraséologie devrait être considérée comme un fait indispensable et inévitable en classe d'ELE, ainsi que nous étudierons diverses propriétés phraséologiques qui rendent difficile tant le travail de l'enseignant que le processus d'apprentissage. Finalement, en partant des idées développées, nous offrirons des considérations méthodiques générales avec d'intéressantes implications didactiques.

Mots-clés: phraséodidactique, processus d'enseignement/apprentissage de la phraséologie, unités phraséologiques, Espagnol Langue Étrangère

SUMARIO: 1. Aspectos preliminares; 2. Acerca del concepto fraseodidáctica; 2.1. La necesidad de la fraseodidáctica como una disciplina independiente; 2.2. Definición y objetivos; 3. La importancia de la fraseología en el aula de E/LE; 4. ¿Por qué la fraseología es un hueso duro de roer tanto para el discente como para el docente?; 5. ¿Cómo enseñar la fraseología de manera más efectiva? Algunas consideraciones generales; 5.1. Relaciones de significado; 5.2. Campos semánticos, redes conceptuales, diagramas; 5.3. Funciones comunicativas; 6. Conclusiones; 7. Bibliografía.

\section{ASPECTOS PRELIMINARES}

Parece obvio que desde los años 70 del siglo $\mathrm{XX}^{1}$, el interés por la fraseología, una disciplina lingüística heterogénea y compleja, se ha venido incrementado notablemente. Es decir, en los últimos años puede observarse una gran proliferación de estudios centrados en diversos aspectos del universo fraseológico como el estatus lingüístico de la fraseología y sus límites, la delimitación de sus unidades, el objeto de estudio, la naturaleza metafórica del hecho fraseológico y su traducción, etc. ${ }^{2}$

$\mathrm{Si}$ bien resulta diáfano que los trabajos de esta índole han supuesto un importante avance en la descripción de la fraseología, no solo en el ámbito español,

\footnotetext{
${ }^{1}$ Como corrobora Corpas Pastor $(2001,21)$, a pesar de que "el despegue de la fraseología como disciplina lingüística data de finales de los setenta", los orígenes de la misma se deben situar a finales de los cuarenta, en los trabajos de J. Casares Sánchez y de V. Vinogradov. Sin embargo, tampoco puede prescindirse de los estudios de los dos grandes precursores de la fraseología del siglo XIX y comienzos del XX: H. Paul y Ch. Bally.

${ }^{2}$ Se trata de los trabajos de Casares Sánchez (1992 [1950]), Zuluaga Ospina (1980), Corpas Pastor (1996), Ruiz Gurillo (2001), Iñesta Mena y Pamies Bertrán (2002) y Dobrovol'skij (2005), entre otros.
} 
sino también internacional; no es menos evidente tampoco que el número de estudios teóricos surgidos hasta hoy en día no es directamente proporcional al de los dedicados al análisis de la vertiente aplicada de la fraseología, esto es, a la fraseodidáctica. Dicho de otro modo, esta faceta de la fraseología ha sido relativamente poco investigada.

Sin embargo, por una parte, conviene precisar que la situación ha ido evolucionando debido al gran auge de investigaciones o estudios que pretenden llenar esta laguna y, por otra, merece la pena poner de relieve que un gran número de las propuestas didácticas no trazan una línea divisoria tajante entre las distintas esferas que componen el universo fraseológico, sino que las tratan indistintamente. De ahí que las estructuras convencionalizadas y estables, que se caracterizan por una fuerte idiomaticidad y una motivación difícilmente descifrable, no se distingan ni de las unidades parcialmente idiomáticas, basadas en una metáfora transparente, ni de las combinaciones pluriverbales institucionalizadas, pero no idiomáticas, esto es, las colocaciones, ni tampoco de las fórmulas rutinarias, es decir, estructuras prefabricadas que dependen de una situación comunicativa concreta.

Al señalar la gran heterogeneidad del hecho fraseológico, nos parece menester recalcar que somos conscientes del considerable número de taxonomías de las UF surgidas hasta hoy en día. No obstante, en el presente estudio tomaremos como punto de partida la clasificación propuesta por Corpas Pastor (1996), muy difundida en el ámbito hispánico, según la cual el universo fraseológico está compuesto por tres esferas: 1) colocaciones, 2) locuciones y 3) enunciados fraseológicos que se dividen en diversas subclases. Asimismo, dada la naturaleza del presente trabajo, a nuestro juicio, parece prescindible profundizar en aspectos teóricos correspondientes a la delimitación o la clasificación de las unidades fraseológicas (en adelante UF).

Así pues, el objetivo del presente artículo es, por un lado, ofrecer una perspectiva general de la fraseodidáctica y, por el otro, demostrar que las UF no son tan fieras como las pintan, esto es, que a pesar de su complejidad interna y de su heterogeneidad conceptual, se pueden introducir en el aula de manera productiva y eficaz, incluso a partir del nivel inicial. Por lo tanto, intentaremos evidenciar que la "aventura" con la fraseología no ha de empezarse en los niveles más avanzados, como el intermedio o superior, sino desde el comienzo.

Teniendo en cuenta lo expuesto, en el apartado segundo intentaremos acercar al lector el concepto de fraseodidáctica, concepto comúnmente usado en el ámbito internacional; es decir, presentaremos la naturaleza del mismo, así como los objetivos que pretende lograr. A continuación, en el siguiente apartado trataremos de responder a las preguntas que nos parecen fundamentales a la hora de hablar de la enseñanza de la fraseología en el aula de español como lengua extranjera (en adelante E/LE): ¿por qué es tan importante introducir las UF en clase?, ¿qué valor tiene la fraseología en el aula de E/LE? En el apartado cuarto indagaremos en las propiedades internas del universo fraseológico, esto es, demostraremos por qué la 
fraseología constituye un verdadero escollo no solo para el alumno, sino también para el profesor. El bloque quinto tiene por objetivo dar unas claves para mejorar el proceso de enseñanza-aprendizaje de las UF en el aula de E/LE. En esta parte del trabajo se pretende ofrecer algunas consideraciones generales acerca de la presentación, descodificación, comprensión y memorización de las UF. En otras palabras, dichas observaciones iniciales no solo podrán ayudar al profesor a enfrentarse a este tipo de unidades, sino que también pueden hacer que el aprendizaje de la fraseología sea menos tortuoso y más motivador para el alumno, es decir, que el aprendiz incremente su interés por esta parcela lingüística.

\section{ACERCA DEL CONCEPTO FRASEODIDÁCTICA}

\subsection{La necesidad de la fraseodidáctica como una disciplina independiente}

Si bien parece obvio que el origen de la fraseodidáctica "se sitúa en la glotodidáctica o didáctica de las lenguas, en donde emergen las primeras manifestaciones de interés de docentes de lenguas extranjeras por la parte más viva de la lengua que enseñan" (González Rey, 2012, 67), no es menos evidente que la denominación fraseodidáctica, de origen germánico (phraseodidactik), fue acuñada por Kühn (1987) y después consolidada entre fraseológos alemanes como Lüger (1997) y Ettinger (1998). Sin embargo, no es un término comúnmente usado en el ámbito español. Dicho de otro modo, la mayoría de los lingüistas españoles, refiriéndose al fenómeno en cuestión, prefieren utilizar otra designación: la didáctica o la enseñanza de la fraseología ${ }^{3}$.

Así pues, como corrobora González Rey $(2012,67)$, aunque la fraseodidáctica suele definirse como la didáctica de la fraseología merece la pena introducir una matización entre ambos términos. De ahí que proponga diferenciar tres etapas en la historia de la constitución de la fraseodidáctica:

1) La didáctica de la fraseología, representando la didáctica una disciplina aplicada de la lingüística, dedicada a la enseñanza-aprendizaje de lenguas y siendo la fraseología el ámbito de las expresiones hechas de una lengua.

2) La didáctica de la fraseología, siendo la fraseología una disciplina lingüística y la didáctica un ámbito de aplicación.

3) La fraseodidáctica, una rama de la fraseología aplicada como lo es también la fraseografía.

Dicho de otro modo, la didáctica de la fraseología resulta ser la etapa en la que se suscita el interés por los fraseologismos en el seno de una lengua objeto de enseñanza por parte de aprendices de lenguas maternas (en adelante LM) y extranjeras (en adelante LE). La didáctica de la fraseología es el período en el que nace el interés de especialistas, tanto fraseólogos como paremiólogos, por una

3 Véanse: Forment Fernández (1998), Penadés Martínez (1999), Ruiz Gurillo (2000), Navarro (2004), Gutiérrez Quintana (2004) y Fernández Prieto (2005), entre otros. 
cuestión que plantean en términos relativos; y, la tercera etapa, la fraseodidáctica, se constituye como una rama aplicada que permite a docentes y especialistas situar la didáctica de la fraseología en el centro de sus preocupaciones con el objetivo de que ocupe un lugar propio dentro de la fraseología (ibídem, 67-68).

Asimismo, cabe recalcar que el término fraseodidáctica fue utilizado por primera vez en castellano por Larreta Zulategui (2001) y, después, por Corpas Pastor (2003), no obstante, ambos lingüistas no han indagado en el tema en cuestión, solo han señalado un creciente interés por esta vertiente aplicada de la fraseología. Hoy en día, la fraseodidáctica, empieza a emerger en el ámbito español debido, mayoritariamente, a los trabajos de González Rey $(2004,2006,2012)$ y al proyecto FRASEONET, creado en 2007 en la Universidad de Santiago de Compostela, que se inscribe dentro de la lingüística aplicada, más concretamente en el ámbito de la didáctica de las expresiones fijas en LM y LE, cuyo fin es el de elaborar material didáctico para la enseñanza de dichas expresiones fijas hasta el nivel C2 del Marco Común de Referencia para las Lenguas (en adelante MCRL).

En conclusión, la fraseodidáctica en los últimos años se ha convertido en un campo de estudio independiente, de carácter interdisciplinar que combina elementos de la fraseología, la enseñanza de lenguas, la lingüística contrastiva, así como la psicolingüística y la sociolingüística.

\subsection{Definición y objetivos}

Merece la pena recalcar, siguiendo a González Rey (2012, 76), que la fraseodidáctica no solo representa una denominación, sino una posición como fraseólogo frente a la didáctica de la fraseología: "la fraseodidáctica consiste, ciertamente, en la didáctica de la fraseología de una lengua, pero también en la didáctica de una lengua a través de su fraseología" (ibídem). Nosotros, añadiríamos, al respecto, que se trata de la didáctica tanto de una lengua propiamente dicha, como de la cultura de una comunidad lingüística dada reflejada en su caudal fraseológico.

Así pues, el concepto en cuestión atañe a la adquisición/enseñanza/aprendizaje, tanto dentro de la LM como de la LE, de una amplia gama de unidades fijas que se encuentran en el centro y en la periferia del universo fraseológico. Con el propósito de lograr la máxima competencia comunicativa del discente, el estudio de este tipo de unidades debe estar precedido de una introducción de índole cultural, esto es, ha de incluir información sobre "a sociedade, os costumes, as mentalidades, a cultura implicada en cada tipo" (González Rey, 2006, 139).

Además, como corrobora Ettinger $(2008,96)$ "A investigación nesta disciplina non é un fin en si mesma, senón un medio para alcanzar un fin". Es decir, el objetivo principal de la fraseodidáctica consiste en que las UF se reconozcan, aprendan y empleen como unidades poliléxicas con significado propio y, que lo aprendido, se pueda aplicar de manera adecuada a la situación comunicativa. 
De ahí que la fraseodidáctica tenga la finalidad de descubrir las intenciones particulares del emisor. El discente ha de saber por qué un hablante nativo en un contexto comunicativo concreto decide recurrir a una UF y, en cambio, no opta por emplear la paráfrasis de la misma. Así pues, "o fin da fraseodidáctica é indicarlle ao alumno quen usa este fraseoloxismo, en que situación e con que intención" (ibídem: 97). Dicho de otro modo, se han de explicar las diferencias semánticas y pragmáticas entre las UF y las unidades léxicas simples y no figuradas.

\section{LA IMPORTANCIA DE LA FRASEOLOGÍA EN EL AULA DE E/LE}

Parece incuestionable el hecho de que el componente fraseológico, hoy en día, se ha convertido en un elemento imprescindible en la didáctica de las LE. Dicho en otros términos, resulta imposible dominar un idioma extranjero sin saber las UF, es decir, no solo tener el conocimiento de ellas, sino también la capacidad para utilizarlas en los contextos comunicativos adecuados.

Debido a las directrices generales sobre la competencia léxica ${ }^{4}$ recogidas en el MCERL (2002) y en el Plan Curricular del Instituto Cervantes (2007), la fraseología está adquiriendo cada vez mayor importancia en la clase de E/LE. Como recalca López Vázquez (2010, en línea):

Las expresiones fijas han sido tratadas tradicionalmente como un fenómeno anecdótico y, por lo tanto, de poco interés a la hora de aprender una nueva lengua. Sin embargo, las investigaciones más recientes demuestran que la competencia fraseológica tiene una gran importancia en los intercambios comunicativos de cualquier comunidad lingüística y, en consecuencia, el componente fraseológico debe ocupar un lugar fundamental en la adquisición de una lengua extranjera.

Pero, ¿por qué el componente fraseológico resulta ser tan importante e indispensable en el aula de E/LE? ¿Cuál es su potencial educativo? ¿Cómo la inclusión de la fraseología en la clase de LE puede mejorar la competencia comunicativa de los discentes? En el presente apartado queremos dar respuesta a estas tres cuestiones primordiales.

Tal y como pone de manifiesto Olimpio de Oliveira (2004, en línea), "el conocimiento fraseológico contribuye al desarrollo de la competencia comunicativa

\footnotetext{
${ }^{4}$ MCERL, a pesar de referirse a los distintos componentes adscribibles claramente al universo fraseológico, no utiliza el término fraseología, sino que habla de los elementos léxicos que comprenden "expresiones hechas, que se componen de varias palabras que se utilizan y se aprenden como un todo. Las expresiones hechas incluyen: fórmulas fijas [...] que comprenden refranes y proverbios, etc. [...], modismos; a menudo: metáforas lexicalizadas, semánticamente opacas [...], estructuras fijas, aprendidas y utilizadas como conjuntos no analizados, en los que se insertan palabras o frases para formar oraciones con sentido [...], otras frases hechas [...]” (MCERL, 2002, 108).
} 
del aprendiz, a que este tenga una performance lo más parecida posible a la de un nativo y a su interacción social". Dicho de otro modo, si el discente se expresa con fluidez en una LE, tiene muy buen conocimiento de las reglas gramaticales, así como sabe identificar las UF en un determinado tipo de texto (oral o escrito), pero, o bien no puede captar los diversos matices del significado fraseológico, o bien no posee la habilidad de seleccionar de manera adecuada las UF que se ajusten al contexto comunicativo determinado, nunca alcanzará una competencia comunicativa óptima. Es decir, su discurso no se asemejará, en ningún caso, al de un hablante nativo, sino que sonará forzado, ensayado, superficial o, no idiomático, tal como lo denomina Lennon (1998,12, apud. Olimpio de Oliveira, 2004, en línea).

Así pues, el mal uso de las UF puede romper convenciones de cortesía, llevar a malentendidos y perjudicar el proceso de comunicación. De ahí que la enseñanza contextualizada de la fraseología resulte ser lo primordial en el aula de E/LE. Solo mediante la referencia a la naturaleza eminentemente pragmática de las UF, esto es, a las funciones que desempeñan en el discurso, al registro en que suelen aparecer o a las restricciones de uso que presentan, resulta posible mejorar la competencia comunicativa del discente. En otras palabras, en el proceso de enseñanzaaprendizaje de la fraseología no puede descartarse la faceta pragmática de la misma. García Muruais $(1997,364)$ presenta, al respecto, una serie de motivos por los cuales las UF resultan ser pragmáticamente esenciales, son "elementos privilegiados":

a) Desempeñan tanto la función referencial como la expresiva, así como contribuyen a la economía discursiva, puesto que se pueden aplicar en diferentes contextos.

b) Proporcionan una mayor espontaneidad, fluidez y autenticidad al discurso oral, que resulta no solo más vivo, sino también más auténtico.

c) Presentan un carácter eufemístico, por lo que su uso hace más aceptable socialmente el manifestar la valoración personal.

d) Son descodificadores, puesto que permiten comprender lo que se quiere decir a partir de lo que se dice.

e) Dan cuenta de informaciones socio-culturales, reflejan aspectos de la idiosincrasia de los españoles, que resultan obvios para los nativos, pero no para los extranjeros.

Todo lo mencionado confirma que el conocimiento pragmático de las UF facilita la interacción social de un estudiante y le proporciona recursos útiles gracias a los cuales puede expresar o interpretar ciertas intenciones o connotaciones que van más allá de la mera denotación (ibídem, 365).

Al señalar la gran importancia del componente fraseológico, tampoco puede prescindirse de su considerable caudal lingüístico y cultural. Si bien resulta obvio que las UF están cada vez más presentes en distintos géneros textuales, no es menos evidente que reflejan la historia, los hábitos y las costumbres, así como la manera de pensar y conceptualizar el mundo por parte de los hablantes. Por tanto, para 
entender las UF de una lengua es necesario conocer tanto el universo cultural de sus hablantes y su visión del mundo como la competencia metafórica de estos. En general, la fraseología ha sido concebida como lo más idiosincrásico y particular de una comunidad dada. No obstante, como señala Timofeeva (2013, 324- 325), a pesar de que existe una fuerte vinculación entre el significado de una UF y el bagaje cultural compartido por los hablantes nativos de una lengua que es adquirido y desarrollado desde la infancia, las UF no deberían contemplarse como un problema, sino como una solución, dado que a través de ellas se puede tener acceso directo a muchos aspectos culturales que deberíamos tratar en clase.

Así pues, debido a que las UF forman parte integral de la cultura de un pueblo, son preservadores naturales de las creencias, tradiciones y símbolos de un pueblo (cfr. Luque Durán y Manjón Pozas, 2002, en línea), “acceder a un idioma sin un conocimiento de estas expresiones se convierte en una tarea imposible" (Serradilla Castaño, 2000, 657). De ahí que la inclusión de la fraseología en el aula de E/LE, a nuestro juicio, sea un hecho incuestionable. Parece indudable que las UF son una buena vía para introducir en clase aspectos culturales, puesto que permiten "ver el nuevo idioma desde otra perspectiva y con un conocimiento más profundo de la realidad en la que están inmersos sus hablantes" (ibídem, 660).

En conclusión, por muy difícil, lento o arduo que resulte el proceso de enseñanza-aprendizaje de este tipo de unidades, el profesor no puede y no debe dejarlas de lado, dejarlas para cuando las ranas crien pelo.

Sin lugar a dudas, las UF forman parte del lexicón mental de los hablantes de una comunidad sociocultural dada, son "ventanas que dan al mundo", dado que remiten a las imágenes mentales que subyacen al significado figurado de unidades de esta índole. Dichas imágenes están almacenadas en la memoria de los hablantes $\mathrm{y}$, a veces, parecen estar determinadas culturalmente, esto es, con mucha frecuencia resultan discrepantes e irreconciliables entre las dos (o más) culturas ${ }^{5}$. Por ello, la enseñanza-aprendizaje de la fraseología es un proceso lleno de obstáculos y dificultades, no solo para el profesor, sino también para el estudiante. Los aspectos concernientes a la complejidad del universo fraseológico que influyen, tanto en la labor docente como en el proceso discente, serán tratados más detalladamente en el capítulo siguiente.

\section{4. ¿POR QUÉ LA FRASEOLOGÍA ES UN HUESO DURO DE ROER TANTO PARA EL DISCENTE COMO PARA EL DOCENTE?}

A pesar de que los estudios de la fraseodidáctica, tal y como ya hemos mencionado, se han multiplicado recientemente, no todas las aplicaciones didácticas de las UF surgidas hasta hoy en día han resultado igualmente apropiadas, dado que

5 Para profundizar en el aspecto de la aparente similitud conceptual de las UF translingüísticas véanse Dobrovol'skij (2005) y Szyndler (2014). 
"en ocasiones, la aproximación descontextualizada a estas unidades, así como el empleo de una metodología poco adecuada para su enseñanza, ha dificultado el trabajo de los estudiantes" (Mendoza Puertas, 2011, en línea).

Parece constatarse que la fraseología en clase de E/LE es una cuestión difícil y complicada también para el profesor que se enfrenta con las UF, puesto que desde el principio encuentra muchos escollos y desafíos que dificultan su labor docente. Como admite Navarro (2004), "el profesor que decide trabajar en el aula las UF se encuentra desorientado respecto a las combinaciones que tiene que trabajar y de acuerdo con qué criterios".

Así pues, la opinión de que el componente fraseológico resulta difícil tanto para enseñarlo como para aprenderlo parece estar muy difundida entre los fraseodidácticos. No obstante, hemos de preguntarnos: ¿a qué se debe esta dificultad?, ¿cuáles son sus causas?

Por ejemplo, según Wray (2000, 468, apud. Olimpio de Oliveira, 2004, en línea), uno de los posibles motivos por los cuales la adquisición de las UF no resulta ser un camino de rosas es la escasa experiencia del aprendiz con este tipo de unidades. Como afirma Olimpio de Oliveira (2004, en línea), cuya opinión compartimos, es imprescindible que se desarrollen más investigaciones sobre las UF, dado que la escasez de estudios empíricos sobre el tema en cuestión lleva a que hayan recibido poca atención en la didáctica de la LM y LE a lo largo de los años. Asimismo, en algunos de los trabajos "se observa cierta confusión tanto terminológica como conceptual, ambigüedad que, en ocasiones, se refleja en las propuestas metodológicas" (Navarro, 2004, en línea). De ahí que el profesor no sepa cómo explotar de modo efectivo el universo fraseológico en el aula de E/LE. Para que la enseñanza de las UF no sea un hecho marginal, sino central, es menester que el docente primero comprenda el hecho fraseológico y aprenda sus componentes y, después, diferencie sus unidades y domine su uso (González Rey, 2006, 142).

Otro factor que influye en la complejidad de la enseñanza-aprendizaje de la fraseología es la propia naturaleza de las UF, su objeto de estudio, esto es, sus características formales, semánticas o pragmáticas, a las que ya nos hemos referido.

En lo que atañe a los aspectos formales, Olimpio de Oliveira (2004, en línea) opina que "el rasgo de fijación, es decir, el hecho de que muchas UF se reproducen siempre de la misma manera y no admiten variación en su estructura, puede ser un obstáculo que los aprendices deben afrontar", puesto que cada modificación de la estructura formal de una UF puede cambiar el significado de la misma o destruir su carácter fraseológico. Lo ilustraremos con un ejemplo. Si en la UF abrir alguien el ojo cambiamos el número del objeto directo, esto es, abrir alguien los ojos, el significado figurativo global también será distinto: 'Estar advertido para que no le engañen' $(D R A E)$ y 'Conocer las cosas como son, para sacar provecho y evitar las que pueden causar perjuicio o ruina' $(D R A E)$, respectivamente.

Sin embargo, Olimpio de Oliveira (ibídem) hace una puntualización más. Es decir, corrobora que resulta imposible afirmar, con toda seguridad, que la propiedad 
de fijación fraseológica impide la enseñanza de las UF, dado que no existen estudios empíricos que lo convaliden. El mismo punto de vista lo comparte Timofeeva $(2013,324)$, según la cual "las diversas características de las UF que se presentan como fuentes de su complejidad didáctica pueden verse, a la vez, como potentes mecanismos de aprendizaje que deberían facilitar el proceso", puesto que pueden cumplir una función mnemotécnica.

En lo que concierne al plano semántico de las UF, cabe recalcar que se pueden mencionar muchos factores que contribuyen a la complejidad fraseológica y pueden dificultar la enseñanza y la adquisición de estas unidades: la forma en que se construye su significado, la naturaleza metafórica, la cuestión de la interpretación estándar y de la petrificación semántica (Olimpio de Oliveira, 2004, en línea). Dado que el significado de la mayoría de las UF, sobre todo el de las locuciones, no es compositivo en el sentido de que no equivale a la suma de significados de sus elementos constitutivos, las UF que más dificultades entrañan son las que presentan un alto grado de idiomaticidad y casi nula, o borrosa, motivación, como, por ejemplo, tomar las de Villadiego o más sucio que una araña. Como señala Gross (1996), las estructuras poliléxicas fijadas constituyen un verdadero obstáculo para el aprendiz, quien, a pesar de conocer y entender el significado de cada uno de los componentes de una UF dada, no puede captar su significado global. Dicho de otro modo, si el discente se encuentra con una UF opaca o poco motivada, no sabrá cómo analizar su sentido, puesto que "su lectura idiomática es como un tesoro enterrado en una isla desierta. No hay caminos para llegar a él, o estos están llenos de escollos y de dificultades de interpretación" (Ruiz Gurillo, 2001, 21). Además, un gran número de locuciones es polisémico, esto es, posee más de un significado que solo se actualiza en un contexto determinado, lo que también aumenta su complejidad semántica.

No obstante, los impedimentos semánticos concernientes a la descodificación de las UF arriba mencionados, no imposibilitan totalmente la adquisición de este tipo de unidades por parte del aprendiz:

[...] el alumno, que ya desde el nivel perceptivo suele notar la índole de la combinación, está mucho más motivado ante una expresión idiomática que ante las fórmulas discursivas, rutinarias y colocaciones ya que, sobre todo en el caso de las lenguas afines, no tiene demasiadas dificultades de comprensión para una gran parte de estas lexías complejas, por lo que le falta estímulo para fijarse en ellas y así incorporarlas en su aprendizaje activo (Navarro, 2004, en línea).

Asimismo, cabe resaltar que en opinión de Timofeeva (2013, 323), la adquisición de las UF resulta dificil para un hablante no nativo, no tanto por los motivos lingüísticos, sino por los sociales: 
A veces, el uso de ciertos procedimientos fraseológicos puede suponer un fracaso pragmático para un extranjero, como es el caso de locuciones que se refieren a realidades culturales específicas, únicas que suscitan asociaciones connotativas percibidas como exclusivas por y para la comunidad en cuestión (v. g., dar el paseo [a alguien], 'en la Guerra Civil de 1936: llevárselo por la fuerza y matarlo sin juicio previo’, DFDEA), y también el de las UF desautomatizadas [...].

Así pues, podemos corroborar que los problemas de aprendizaje de la fraseología atañen tanto al nivel de descodificación del significado fraseológico como al nivel de producción lingüística, en el que el estudiante tiene que usar de forma apropiada las UF "ajustándolas" a las situaciones comunicativas concretas.

Una vez presentados los escollos y las dificultades que el proceso de enseñanzaaprendizaje de la fraseología lleva consigo, se ha de plantear una serie de preguntas de índole práctica: ¿cómo enseñar la fraseología de manera más efectiva? ¿A qué recursos didácticos puede recurrir el profesor para que el aprendizaje de UF sea más fácil y menos agobiante? ¿Qué técnicas mnemotécnicas puede usar? ¿Qué tipo de UF debe enseñar y cuándo, es decir, a qué nivel ha de introducirlas en clase? Dichas cuestiones las abordaremos en el apartado siguiente.

\section{5. ¿CÓMO ENSEÑAR LA FRASEOLOGÍA DE MANERA MÁS EFECTIVA? ALGUNAS CONSIDERACIONES GENERALES}

Sin lugar a dudas, la gran complejidad interna del universo fraseológico, señalada en los capítulos anteriores, es un factor principal que dificulta el proceso de enseñanza-aprendizaje de las UF. No obstante, esto no significa que no exista ningún método que facilite la labor del docente, así como que favorezca la adquisición de la fraseología por parte del aprendiz. Uno de ellos son los llamados tres pasos fraseodidácticos propuestos por Kühn (1992, apud. Ettinger, 2008, 107) $\mathrm{y}$ aplicados con mucho éxito por profesores de todo el mundo. Se trata de un procedimiento que permite reconocer, descifrar y emplear las UF y al que se puede recurrir tanto en la enseñanza de LM como en la de LE.

En el primer paso, en el que se activan todos los procesos de descodificación, el aprendiz tiene que identificar un fraseologismo dado en un texto auténtico oral o escrito. Cabe recalcar que las posibles anomalías morfosintácticas o las incompatibilidades semánticas le pueden servir de ayuda, esto es, pueden facilitarle el reconocimiento de una UF determinada. En lo que concierne al segundo paso, este tiene por objetivo comprender o descifrar el significado fraseológico que aparece en una situación comunicativa dada (la fase de reproducción); mientras que en el paso tercero el discente debe usar la UF que acaba de aprender en un contexto parecido (la fase de producción). Parece indudable que la aplicación de estos tres 
pasos, que trajeron "un aire fresco" a la enseñanza de lenguas ${ }^{6}$, desarrolla la competencia fraseológica productiva del alumno, dado que las UF se introducen (y aprenden) no de forma pasiva, sino activa o, más bien, interactiva. Dicho de otro modo, el estudiante no solo "recibe" las UF, sino que también tiene que "producirlas" en un contexto concreto.

Así pues, tal y como propone Ettinger $(2008,108)$, quien modificó sutilmente la propuesta de Kühn, primero se deben seleccionar las UF dentro de un contexto, después explicar las diversas posibilidades de uso de las mismas, indicar las restricciones gramaticales y clasemáticas $\mathrm{y}$, por último, dar información sobre el registro y funciones que desempeñan las UF en el discurso e intentar encontrar un concepto clave para cada UF a partir de un esquema onomasiológico, como, por ejemplo PODER, IRA, ENFERMEDADES. Es imprescindible que el alumno vea, a través de los ejemplos, que las UF no se pueden explicar simplemente parafraseándolas, dado que, en la mayoría de los casos, añaden un valor semántico diferente y están limitados en su uso por cuestiones pragmáticas y situacionales. De ahí que se deba trabajar con textos reales (textos periodísticos, canciones, anuncios, bitácoras digitales, chats), que permiten al estudiante descubrir diversos contextos correspondientes a una UF determinada y, después, emplearla en situaciones comunicativas semejantes. Solo de esta manera el aprendiz podrá desarrollar su competencia fraseológica, una parte integrante de la competencia comunicativa, que se concibe como "el hecho de conocer las diferentes UF de una lengua, y saber interpretarlas e integrarlas en un discurso propio, oral o escrito, adecuado según el cotexto, el contexto, la relación con el interlocutor, las normas sociales y nuestros propósitos de interacción" (Solano Rodríguez, 2004, 411).

Además, como observa Ettinger $(2008,108)$, al discente le resulta muy útil comenzar con unidades de la LM y luego pasar a la LE, dado que, en muchos casos, se pueden encontrar UF similares, tanto desde el punto de vista sintáctico como semántico. Es decir, se trata de los europeísmos fraseológicos, cuyo origen puede ser natural (esp. cortarle a uno las alas- pl. podciać komuś skrzydta), cultural (esp. la caja de Pandora- pl. puszka Pandory), o bien una mezcla de ambos (esp. Ojo por ojo, diente por diente, pl. oko za oko, ząb za zab) (Corpas Pastor, 2003, 249-250). No obstante, esto no quiere decir que las UF de dos (o más) lenguas, que se asemejan tanto desde el punto de vista del plano formal como del conceptual, no presenten dificultades en la adquisición de la fraseología, puesto que, a veces, su similitud conceptual resulta solo aparente. Es decir, si se investigan en detalle, recurriendo a su ámbito de uso, presentan notables discrepancias y solapamientos en lo que se refiere al nivel sintáctico, conceptual o pragmático. Por ejemplo, la locución española levantarse con el pie izquierdo y su pseudoequivalente polaca

\footnotetext{
${ }^{6}$ No obstante, conviene mencionar que la propuesta de Kühn también fue sometida a la crítica, véanse, al respecto, Lüger (1997) y Laskowski (2009).
} 
wstać lewa noga son falsos amigos fraseológicos, dado que, aunque evocan la misma imagen mental y se caracterizan por una similitud morfológica y ortográfica, difieren semánticamente. Es decir, el significado figurado de la UF española se puede definir como 'tener mala suerte' $(D D F H)$, mientras que el de la UF polaca se entiende como 'estar de mal humor, enfadado' (MSJP). Tal y como corrobora Ettinger $(2008,112)$ :

A equivalencia formal entre determinadas linguas debe interpretarse, con todo, de forma moi restritiva para fins fraseolóxicos e, especialmente, fraseodidácticos, xa que diferenzas formais menores poden dar lugar a imaxes insólitas ou mesmo erróneas.

Por ello, opinamos que la única manera de que el estudiante pueda distinguir posibles discrepancias entre UF consideradas equivalentes plenas es presentarlas de forma contextualizada, esto es, investigar su funcionamiento en textos auténticos, tan imprescindibles en el aula de E/LE.

En lo que atañe a los modelos metodológicos a los que puede recurrir el docente, a nuestro juicio, estos deberían ajustarse al tipo de las UF con las cuales se enfrenta el discente. Es decir, para que el aprendizaje de la fraseología sea más eficaz y productivo resulta evidente que las colocaciones no pueden trabajarse de la misma manera que las locuciones que manifiestan diversos grados de idiomaticidad, desde la nula hasta la plena, o bien equipararse con las paremias y los refranes. Por ello, opinamos, siguiendo a Ruiz Gurillo (2000, en línea), que las locuciones pueden presentarse recurriendo a expresiones o palabras sinónimas (vid. infra), no obstante, desde nuestro punto de vista, estas siempre deberían aparecer contextualizadas y no de forma aislada, sin referencia ninguna al contexto comunicativo en el que emergen. Las fórmulas rutinarias, fijadas pragmáticamente, se han de enseñar también inmersas en contextos reales, de acuerdo con los actos de habla que presentan, mientras que los refranes, las citas y las paremias deberán estudiarse a partir del significado pragmático que encierran (una verdad general aplicable a una situación concreta) y en la medida de lo posible habrán de observarse también en contextos adecuados.

Además, creemos que algunas UF pueden explotarse de forma efectiva, recurriendo a dibujos o ilustraciones que estimulan el proceso de aprendizaje, ya desde el nivel inicial. Es decir, postulamos que los componentes fraseológicos no se deben ofrecer únicamente a los alumnos que ya poseen un nivel alto del español.

Por ello, a nuestro parecer, para facilitar el aprendizaje de las UF el docente debe introducirlas en el aula de modo gradual, a partir del nivel inicial "adaptando como criterios fundamentales la frecuencia de uso, la estructura sintáctica y las capacidades semántica y pragmática" (Navarro, 2004, en línea). Esto es, en nuestra opinión, las fórmulas rutinarias y discursivas que dependen de una situación comunicativa concreta, así como las colocaciones o las locuciones de idiomaticidad nula, por ejemplo, las comparaciones estereotipadas como lento como una tortuga o 
más blanco que la nieve, pueden enseñarse desde el nivel básico. Por el contrario, las locuciones opacas, cuya motivación resulta difícil de descifrar dado que se ha perdido con el tiempo, así como las paremias y los refranes deberían introducirse en niveles altos, cuando un alumno ya posee un cierto nivel de competencia lingüística y comunicativa. Como corrobora Gutiérrez Quintana (2004, en línea), "el requisito de haber alcanzado un nivel intermedio o superior es sin duda ineludible para captar ciertos matices semánticos y utilizar las locuciones en contextos lingüísticos adecuados".

Así pues, el profesor en vez de utilizar en clase recursos "tradicionales", tan criticados hoy en día, como las famosas listas aisladas de expresiones o ejercicios de huecos, que no adelantan el proceso de adquisición de fraseología, sino que, por el contrario, hacen que sea todavía más tedioso, arduo y pasivo, puede (y debe) recurrir a herramientas de índole semántico-cognitiva, que estimulan el proceso glotodidáctico, esto es, permiten aumentar el grado de dominio de la parcela fraseológica por parte del estudiante de E/LE. A nuestro parecer, dichos recursos resultan particularmente importantes en la enseñanza de las locuciones, sobre todo las altamente idiomáticas y poco transparentes, que más dificultades entrañan. Sin embargo, no descartamos por completo su utilidad didáctica respecto a las demás esferas fraseológicas, como las colocaciones o los enunciados fraseológicos. Además, dados los límites del presente trabajo merece precisar que no se trata de propuestas didácticas concretas, que se puedan llevar directamente al aula, sino de esbozos metodológicos o modelos generales que atañen, sobre todo, a la última fase del proceso didáctico: la de recapitulación o repaso y la de memorización de los contenidos ya presentados.

\subsection{Relaciones de significado}

Ya Penadés Martínez señaló la gran utilidad, tanto para el profesor como para el estudiante, de las relaciones semánticas (hiperonimia/hiponimia, sinonimia y antonimia) en la enseñanza de la fraseología, dado que facilitan no solo la comprensión y la memorización de las UF, sino también su presentación y sistematización en el aula:

los signos lingüísticos que están en relación de antonimia, de hiperonimia-hiponimia y de sinonimia se asocian y constituyen, por ello, series mnemotécnicas virtuales que pueden ser de gran utilidad para memorizar $y$, al final, aprender unidades lingüísticas con rasgos especiales como la fijación formal y semántica que caracteriza a las unidades fraseológicas (Penadés Martínez, 1999, 43).

Así pues, la autora propone una serie de ejercicios que permiten comprobar si el discente ha captado el significado figurado y las condiciones de uso de una UF determinada (ibídem, 37-42). Se trata de actividades en las cuales el estudiante tiene que redactar un texto nuevo en el que aparecen UF sustituyéndolas por su 
significado, señalar las diversas acepciones de una UF homónima (literal y metafórica), ilustrar o escenificar la situación representada por las UF de la LM y de la LE para evitar los calcos y los falsos amigos, escribir una composición o contar una historia utilizando las UF aprendidas o reconocer una UF a partir de una definición y, de manera análoga, sustituir en un texto las definiciones por los correspondientes fraseologismos o emplear UF en pequeñas dramatizaciones, diálogos de libre creación o descripciones sobre temas cotidianos para averiguar si es capaz de insertar las unidades estudiadas de forma oral con cierta soltura.

No obstante, compartimos la opinión de Fernández Prieto $(2005,354)$ según la cual, aunque la selección de material agrupado por relaciones semánticas y morfológicas que nos propone Penadés Martínez es bastante exhaustiva y delimita bien el significado de las UF, se centra demasiado en aspectos de conocimiento lingüístico en vez de proporcionar prácticas contextualizadas que permitan a los alumnos asimilarlas y reutilizarlas. Asimismo, a nuestro parecer, el docente no solo debería explicar el significado de una UF dada, sino también el origen de la misma. Ha de acercar al aprendiz su etimología, lo que también conllevaría una mejor memorización de una UF aprendida, dado que, de esta forma, se podrían "descodificar" los enlaces fraseológicos motivacionales que, a veces, parecen ocultos y profundamente encubiertos.

\subsection{Campos semánticos, redes conceptuales, diagramas}

En primer lugar, queremos poner de relieve que los modelos de explotación didáctica de la fraseología propuestos por algunos autores, en los que se plantea agrupar las locuciones según el significado de uno de sus componentes, no nos parecen muy eficaces y rentables, dado que dan prioridad al significado compositivo y descartan por completo el significado unitario, esto es, global y figurativo de una locución determinada. De ahí que sugiramos sustituir los ejercicios de este tipo por otras actividades en las cuales las UF están clasificadas, o bien según el campo conceptual al que se refieren, o bien por temas.

De lo que no cabe duda es que las palabras no se asimilan y almacenan de forma aislada, sino que su incorporación al lexicón del discente de una LE ha de fundamentarse en el establecimiento de un conjunto de redes formales y semánticas entre las mismas (Mendoza Puertas, 2011, en línea). Así pues, tal y como afirma Baralo (2006, en línea):

Estas redes, enlaces o conexiones son construcciones cognitivas que tienen lugar en el lexicón de todo hablante, dentro de su competencia plurilingüística, por lo que constituyen una motivación y una gran facilitación del aprendizaje léxico, tanto para el reconocimiento de una palabra en el input (lo que escucha o lee) al que está expuesto, como para su recuperación en una situación de producción lingüística, output (lo que dice o escribe). 
Además, la investigadora en cuestión propone una serie de actividades que permiten crear estas redes conceptuales entre unidades léxicas que pueden aplicarse también respecto a las UF: a) localizar cognados, falsos amigos, préstamos semánticos y léxicos, entre la LM y la LE; b) elaborar mapas conceptuales; c) trabajar a partir de textos sobre temas relacionados con la tarea principal (por ejemplo, relacionar conceptos y situaciones con expresiones, completar esquemas conceptuales, cuadros clasificatorios, cuadros sinópticos, elegir entre varias, la palabra o expresión más adecuada al texto y al contexto, etc).

\subsection{Funciones comunicativas}

Tal y como ya hemos mencionado, a nuestro parecer, resulta imposible introducir las UF en clase sin recurrir a las funciones comunicativas que pueden desempeñar en el discurso. De ahí que opinemos que los ejercicios de índole puramente semántica deberían ser complementados por actividades de carácter eminentemente pragmático que permitan al alumno conocer funciones discursivas de una UF dada. De esta manera, no solo se facilitará la comprensión, asimilación y memorización del componente fraseológico por parte del discente, sino que también se introducirá el vocabulario en el aula de E/LE de forma mucho más interactiva. Así pues, compartimos lo señalado por Fernández Prieto (2004, en línea): que las actividades diseñadas alrededor de temas o campos conceptuales como: la salud, el trabajo, la ira, etc., o por la función comunicativa, por ejemplo: mostrar indiferencia, rechazo, saludar, son mucho más atinadas y rentables.

Un buen ejemplo del ejercicio de este tipo es el que aparece en el manual Prisma, nivel B2 (2005) en el cual las UF están agrupadas según el campo conceptual COLORES y, además, quedan vinculadas por la estructura formal que presentan (el esquema ponerse + adjetivos de color) y por la función comunicativa que las une: "expresar un cambio no definitivo con relación al aspecto físico o al estado de ánimo" [Vázquez (coord.), 2005, 59].

\section{CONCLUSIONES}

En el presente trabajo hemos enfocado nuestra atención sobre la vertiente aplicada de la fraseología. Por un lado, hemos indagado en el concepto fraseodidáctica, su definición, su evolución a través del tiempo y sus objetivos; por otro lado, a sabiendas de que el discurso de los hablantes nativos está plagado de UF, las cuales, como señala Timofeeva $(2013,325)$, "constituyen una de las manifestaciones del holismo lingüístico", hemos demostrado que la fraseología en el aula de E/LE es un hecho indispensable y, a la vez, inevitable. Dicho de otro modo, no se puede decir que el estudiante de E/LE haya adquirido una competencia comunicativa óptima sin dominar la competencia fraseológica. Por consiguiente, pese a la gran heterogeneidad y complejidad interna del universo fraseológico, enseñar esta parcela lingüística de forma efectiva no resulta imposible, aunque, sin lugar a dudas, no es coser y cantar para el docente, sino un proceso lleno de 
dificultades de diversa índole. No obstante, a nuestro juicio, por muy grandes que sean dichos escollos, siempre se pueden superar acudiendo, por ejemplo, a los recursos de carácter semántico-cognitivo señalados en el capítulo quinto. De ahí que postulemos, siguiendo a Timofeeva (2013), que las UF no deben contemplarse como obstáculos, sino como elementos de apoyo que permiten al estudiante familiarizarse, no solo con los aspectos lingüísticos, sino también con cuestiones culturales, consideradas idiosincráticas.

Así pues, si bien resulta obvio que la fraseología es un verdadero reto, tanto para el profesor como para el aprendiz, no es menos evidente que no es tan fiero el león como lo pintan, por ello, como señala Fernández Prieto $(2004,355)$, “[...] debemos coger al toro por los cuernos y llevarnos el gato al agua".

\section{BIBLIOGRAFÍA}

BARALO, Marta (2006): "Cómo crear redes entre palabras en el aula de ELE", conferencia presentada en el III Encuentro Práctico de Profesores de ELE Würzburg, 19-20 de mayo de 2006 [en línea]. Disponible en la web: http://www.encuentro-practico.com/pdfw06/baralo.pdf [Consulta: 30 de junio de 2014].

Buitrago, Alberto (2005): Diccionario de dichos y frases hechas (DDFH), Madrid, Espasa Calpe.

CASARES SÁNCHEZ, Julio (1992 [1950]): Introducción a la lexicografía moderna, Madrid, C.S.I.C.

Consejo De Europa (2002): Marco Común Europeo de Referencia para las Lenguas: aprendizaje, enseñanza, evaluación, Madrid: Instituto CervantesMECD, Anaya $(M C R L)$. Disponible en la web: http://cvc.cervantes.es/ensenanza/biblioteca_ele/marco/cvc_mer.pdf [Consulta: 30 de junio de 2014].

CORPAS PASTOR, Gloria (1996): Manual de Fraseología Española, Madrid, Gredos.

CORPAS PASTOR, Gloria (2001): "Corrientes actuales de la investigación fraseológica en Europa", Liburukia, 46, n. ${ }^{\circ} 1$, págs. 21-49.

CORPAS PASTOR, Gloria, (ed.) (2003): Diez años de investigación de fraseología: análisis sintáctico-semánticos, contrastivos y traductológicos, Madrid, Iberoamericana.

DOBROVOL'SKIJ, Dmitrij (2005): "Sobre la equivalencia translingüística de los fraseologismos", en J.d.D Luque Durán y A. Pamies Bertrán (eds.) La creatividad en el lenguaje: colocaciones idiomáticas y fraseología, Granada, Método, págs. 359-380.

EtTINGER, Stefan (1998): "Einige Überlegungen zur Phraseodidaktik", en W. Eismann, (ed.) EUROPHRAS 95. Europäische Phraseologie im Vergleich: Gemeinsames Erbe und kulturelle Vielfalt (Studien zur Phraseologie und Parömiologie, vol. 15), Bochum, Universitätsverlag Dr. N. Brockmeyer, págs. 201-217. 
EtTiNGeR, Stefan (2008): "Alcances e límites da fraseodidáctica. Dez preguntas clave sobre o estado actual da Investigación", Cadernos de Fraseoloxía galega, 10 , págs. 95-127.

FERNÁNDEZ PRIETO, María Jesús (2005): "La enseñanza de la fraseología. Evaluación de recursos y propuestas didácticas", en M.A. Castillo Carballo et al. (eds.) Las Gramáticas y los Diccionarios en la Enseñanza del Español como Segunda Lengua: Deseo y Realidad. Actas del XV Congreso Internacional de ASELE, Sevilla, Universidad de Sevilla, págs. 349-356.

FORMENT FERNÁNDEZ, María del Mar (1998): "La didáctica de la fraseología ayer y hoy: del aprendizaje memorístico al agrupamiento en los repertorios de funciones comunicativas", Espéculo, Universidad Complutense de Madrid [en línea]. Disponible en la web: https://pendientedemigracion.ucm.es/info/especulo/numero10/did_fras.html [Consulta: 30 de junio de 2014].

GARCÍA MURUAIS, María Teresa (1997): "Propuestas para la enseñanza de unidades fraseológicas en la clase de E/LE", en F. Moreno et al. (eds.) Actas del VIII Congreso Internacional de ASELE, La enseñanza del español como lengua extranjera: del pasado al futuro, (Alcalá de Henares 17-20 de septiembre de 1997), Alcalá de Henares, Servicio de Publicaciones de la Universidad de Alcalá, págs. 363-369.

GONZÁLEZ REY, María Isabel (2004): “A Fraseodidáctica: un eido da fraseoloxía aplicada", Cadernos de Fraseoloxía Galega, 6, págs. 113-130.

GoNZÁLEZ REY, María Isabel (2006): "A Fraseodidáctica e o Marco europeo común de referencia paras as Linguas", Cadernos de Fraseoloxía Galega, 8, págs. 123-145.

GONZÁLEZ REY, María Isabel (2012): "De la didáctica de la fraseología a la fraseodidáctica", Paremia, 21, págs: 67-84.

Gross, Gaston (1996): Les expressions figées en français - noms composés et autres locutions, Paris: Collection l'Essentiel Français, Éditions Ophrys.

GUTIÉRREZ QUINTANA, Esther (2004): "La enseñanza de las locuciones a estudiantes de E/LE" [en línea]. Disponible en la web: http://www.filologia.org.br/viiicnlf/anais/caderno09-05.html [Consulta: 30 de junio de 2014].

Instituto Cervantes (2007): Plan Curricular del Instituto Cervantes, Niveles de Referencia para el español (PCIC), Biblioteca Nueva, Madrid.

IÑesta Mena, Eva María, PAMIES BerTRÁn, Antonio (2002): Fraseología y metáfora: aspectos tipológicos y cognitivos, Granada, Método.

KÜHN, Peter (1987): Deutsch als Fremdsprache im phraseodidaktischen Dornröschenschlaf. Vorschläge für eine Neukonzeption phraseodidaktischer Hilfsmittel, Fremdsprachen lehren und lernen, 16, págs. 62-79. 
LARReta Zulategui, Juan Pablo (2001): Fraseología contrastiva del alemán y el español. Teoría y práctica a partir de un corpus bilingüe de somatismos, Frankfurt am Main, P. Lang.

LASKOWSKI, Marek (2009): "Związki frazeologiczne jako problem dydaktyczny na lekcjach języków obcych", Języki obce w szkole, Nr 2, Warszawa, Wydawnictwo CODN.

LÓPEZ VÁZQUEZ, Lucía (2010): "La competencia fraseológica en los textos de los manuales de ELE de nivel superior", Actas del XXI Congreso Internacional de ASELE, Salamanca Del texto a la lengua: la aplicación de los textos a la enseñanza-aprendizaje del español L2-LE. [en línea]. Disponible en la web: http://cvc.cervantes.es/ensenanza/biblioteca_ele/asele/pdf/21/21_0531.pdf

[Consulta: 30 de junio de 2014].

LÜGER, Heinz-Helmut (1997): “Anregungen zur Phraseodidaktik”, Beiträge zur Fremdsprachenvermittlung, 32, págs. 69-120.

LuQUe DuRÁn, Juan de Dios, MANJón POZAS, Francisco José (2002): Claves culturales del diseño de las lenguas: fundamentos de tipología fraseológica [en línea]. Disponible en la web: http://elies.rediris.es/elies16/Claves.html [Consulta: 30 de junio de 2014].

MENDOZA PUERTAS, Jorge Daniel (2011): "De patitas en la calle y sin un duro. Una propuesta didáctica para la enseñanza de las unidades fraseológicas", RedELE Revista electrónica de didáctica/español lengua extranjera, 21 [en línea]. Disponible en la web: http://www.mecd.gob.es/dctm/redele/MaterialRedEle/Revista/2011_21/2011_redELE_21_03Mendoza.pdf?documentId=0901e 72b80dcdfd5 [Consulta: 30 de junio de 2014].

MULTIMEDIALNY SZKOLNY SŁOWNIK JĘZYKA POLSKIEGO WERSJA 2.0. (2008) (MSJP) Warszawa, PWN.

NAVARRO, Carmen (2004): Didáctica de las unidades fraseológicas [en línea]. Disponible en la web: http://www.ub.edu/filhis/culturele/cnavarro.html [Consulta: 30 de junio de 2014].

OliMPIO DE OlIVEIRA, María Eugenia (2004): Fraseología y enseñanza de español como lengua extranjera [en línea]. Disponible en la web: http://www.mecd.gob.es/dctm/redele/Material-

RedEle/Biblioteca/2006_BV_05/2006_BV_05_06Olimpio.pdf?documentId=090 1e72b80e3a050 [Consulta: 30 de junio de 2014 ].

PENADÉS MARTÍNEZ, Inmaculada (1999): La enseñanza de las unidades fraseológicas, Madrid, Arco/Libros.

PENADÉS MARTíNEZ, Inmaculada (2001): "Las fórmulas rutinarias: su enseñanza en el aula de E/LE”, Carabela, 50, págs. 83-101.

ReAl ACADEMia EsPañola, (1992): Diccionario de la lengua española, Madrid, R.A.E.

RUIZ GURILLO, Leonor (2000): "Un enfoque didáctico de la fraseología española para extranjeros", Espéculo, Universidad Complutense de Madrid [en línea]. 
Disponible en la web: http://pendientedemigracion.ucm.es/info/especulo/ele/ fraseolo.html [Consulta: 30 de junio de 2014].

RUIZ GURILLO, Leonor (2001): Las locuciones en español actual, Madrid, Arco Libros.

SERRAdilla CASTAÑo, Ana (2000): "La enseñanza de frases hechas: un método para integrar la cultura en el aula", Actas del XI Congreso Internacional de ASELE, Zaragoza, ¿Qué español enseñar?: norma y variación lingüisticas en la enseñanza del español a extranjeros [en línea]. Disponible en la web: $\mathrm{http}: / / \mathrm{cvc}$. cervantes.es/ensenanza/biblioteca_ele/asele/pdf/11/11_0657.pdf [Consulta: 30 de junio de 2014].

SolANo RodrígueZ, María Ángeles (2004): Unidades Fraseológicas francesas. Estudio en un corpus: la Pentalogía de Belleville de Daniel Pennac. Planteamiento didáctico. Tesis doctoral [en línea]. Disponible en la web: $\mathrm{http}$ //pdf.cervantesvirtual.com/descargapdf/unidades-fraseologicas-francesasestudio-en-un-corpus-la-pentalogia-de-belleville-de-daniel-pennacplanteamiento-didactico--0/?uuid=003caa3a-82b2-11df-acc7-002185ce6064, [Consulta: 30 de junio de 2014].

SZYNDLER, Agnieszka (2014): "Sobre la pseudoequivalencia fraseológica desde una perspectiva cognitivista", Anuario de Estudios Filólogicos, XXXVII, págs. 251-267.

TimofeEvA, Larissa (2013): "La fraseología en la clase de lengua extranjera: ¿misión imposible?”, Onomázein, 28, págs. 320-336.

VÁZQUEZ, Ruth (coord.) (2005): Método de español para extranjeros. Prisma. Avanza (B2), Madrid, Edinumen.

Zuluaga OSPINA, Antonio (1980): Introducción al estudio de las expresiones fijas, Frankfurt am Main, Peter Lang. 